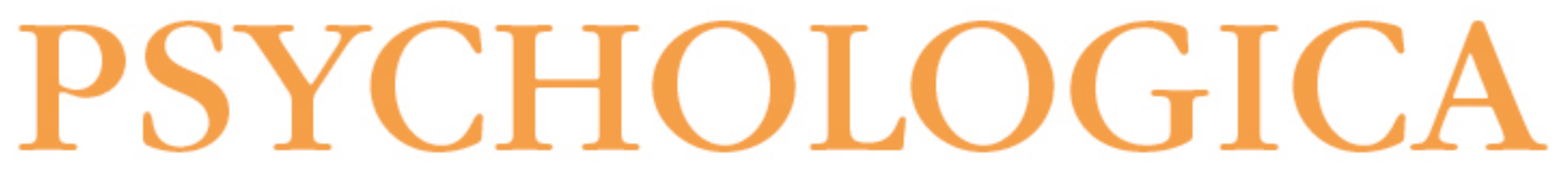

\title{
Preparação para a reforma: responsabilidade individual e colectiva
}

Autor(es): $\quad$ França, Lucia Helena de Freitas Pinho

Publicado por: Imprensa da Universidade de Coimbra

URL

persistente: URI:http://hdl.handle.net/10316.2/5535

DOI: $\quad$ DOI:http://dx.doi.org/10.14195/1647-8606_53_3

Accessed : $\quad$ 26-Apr-2023 02:13:54

A navegação consulta e descarregamento dos títulos inseridos nas Bibliotecas Digitais UC Digitalis, UC Pombalina e UC Impactum, pressupõem a aceitação plena e sem reservas dos Termos e Condições de Uso destas Bibliotecas Digitais, disponíveis em https://digitalis.uc.pt/pt-pt/termos.

Conforme exposto nos referidos Termos e Condições de Uso, o descarregamento de títulos de acesso restrito requer uma licença válida de autorização devendo o utilizador aceder ao(s) documento(s) a partir de um endereço de IP da instituição detentora da supramencionada licença.

Ao utilizador é apenas permitido o descarregamento para uso pessoal, pelo que o emprego do(s) título(s) descarregado(s) para outro fim, designadamente comercial, carece de autorização do respetivo autor ou editor da obra.

Na medida em que todas as obras da UC Digitalis se encontram protegidas pelo Código do Direito de Autor e Direitos Conexos e demais legislação aplicável, toda a cópia, parcial ou total, deste documento, nos casos em que é legalmente admitida, deverá conter ou fazer-se acompanhar por este aviso. 
NÚMERO 53

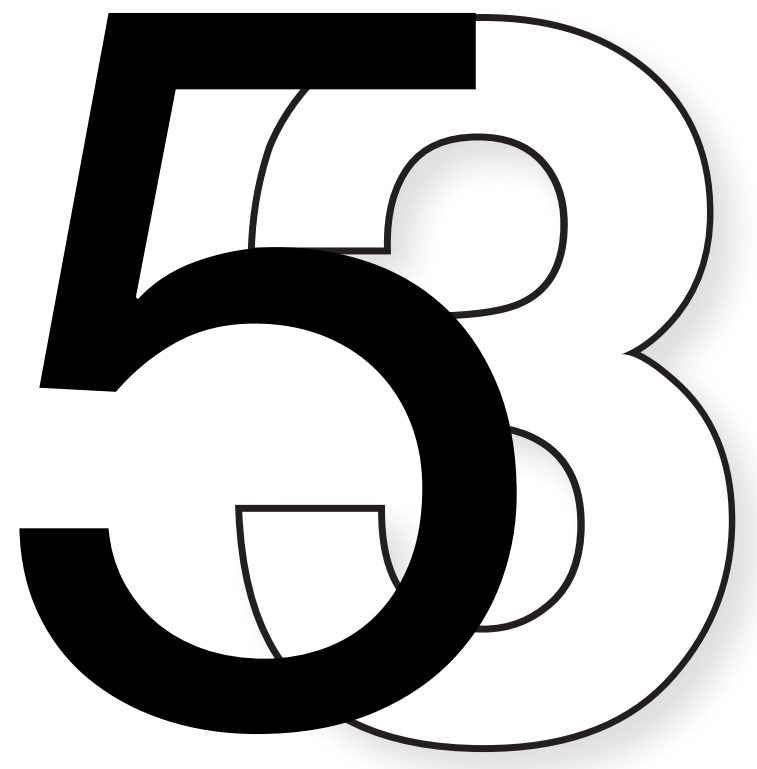

IMPRENSA DA UNIVERSIDADE DE COIMBRA

FACULDADE DE PSICOLOGIA E DE CIÊNCIAS DA EDUCAÇÃO DA UNIVERSIDADE DE COIMBRA 


\title{
Preparação para a Reforma: Responsabilidade individual e colectiva
}

\author{
Lucia Helena de Freitas Pinho França'
}

Uma das conseqüências do avanço da medicina e da queda da natalidade foi o aumento da expectativa de vida, observado tanto nos países desenvolvidos quanto nos periféricos. Assim, o maior desafio para este século será manter as pessoas mais velhas activas, independentes e participativas, como recomendado pela Organização Mundial de Saúde. No mundo do trabalho, é preciso garantir a livre escolha do trabalhador frente a sua aposentadoria ou continuidade no mercado, e as medidas a serem tomadas para seu bem-estar no futuro. Neste artigo são abordados os preconceitos contra a idade e as atitudes frente à aposentadoria, a atualização da mão-de-obra mais velha, e o Programa de Preparação para a Reforma (PPR). São discutidos ainda os projetos intergeracionais que intercambiam a experiência e o conhecimento dos mais jovens e mais velhos, como um processo de transferência e valorização do patrimônio humano e histórico da organização.

PALAVRAS-CHAVE: reforma; atitudes; preconceitos; Programas de Preparação para a Reforma; trabalho; projetos intergeracionais.

\section{Introdução}

O extraordinário aumento na sobrevida é um dos maiores ganhos deste século. Este fenômeno está sendo observado tanto nos países desenvolvidos quanto nos periféricos, e requer uma profunda análise dos aspectos que se sobressaem à nova pirâmide demográfica. Um dos grandes desafios é viabilizar o sustento dos idosos pelos governos, quer pela dificuldade no pagamento das pensões, quer pelos altos custos dos serviços médicos e sociais.

Neste sentido, torna-se fundamental que os trabalhadores sejam apoiados à medida que envelhecem, estimulando a sua mobilidade, independência e saúde. Esta é uma das mais veementes recomendações da OMS (Organização Mundial

\footnotetext{
1 Professor titular do Mestrado em Psicologia da UNIVERSO - Universidade Salgado de Oliveira - Rio de Janeiro - Brasil - luciafranca@luciafranca.com
} 
de Saúde) e da ONU (Organização das Nações Unidas), adoptadas no último encontro mundial sobre envelhecimento (2002, Madrid).

Sendo assim, a reforma vem sendo postergada no mundo inteiro, e seu conceito está sendo modificado. Hoje muitas pessoas de 60 anos são percebidas como ainda 48 jovens e se mantêm em plena forma sabendo que serão centenárias! Sob o ponto de vista organizacional, o processo de envelhecimento foi tão rápido que não houve tempo suficiente para as empresas serem convencidas de que os trabalhadores mais velhos podem manter-se tão actualizados, motivados e habilidosos quanto à capacidade e à experiência que já provaram possuir. Porém, as oportunidades de trabalho após a reforma não estão ainda muito disponíveis. Em 2006, apenas $33 \%$ dos homens portugueses de 60 anos ou mais estavam na força produtiva, contra $18 \%$ das mulheres na mesma faixa etária (United Nations, 2006).

A reforma pode ser uma oportunidade para a adopção de um estilo de vida mais saudável, com a inserção de actividades físicas, lazer, mais tempo para investimentos, passatempos, voluntariado, amizades, intensificação do convívio familiar, e uma atividade laborativa a meio tempo. A planificação para a reforma, é, pois, fundamental para todos os cidadãos como continuidade da planificação para a vida, devendo ser estimulado nas escolas, universidades e nas organizações.

No tocante à planificação individual, a renda mensal satisfatória e a continuidade do plano de saúde na reforma são primordiais para garantir a mobilidade e a independência. Na planificação colectiva, as atitudes frente à reforma perpassam pelo ambiente e pelo contexto sócio-econômico e político do país. Dependem do valor atribuído aos seus cidadãos nas diversas fases da vida, e dos preconceitos da sociedade em relação ao envelhecimento.

\section{Preconceitos contra as pessoas mais velhas e ao envelhecimento}

Como definido por Allport (1954) o preconceito é uma hostilidade ou antipatia dirigida a pessoas ou a um grupo de pessoas, devido a generalizações incorretas. O preconceito têm três componentes: crenças, sentimentos e tendências comportamentais. De modo geral, o ponto de partida do preconceito é uma generalização superficial, denominada estereótipo. O preconceito pode englobar aspectos distintivos de uma pessoa, tais como: idade, raça, religião, gênero, profissão, local de residência, e outros.

Os preconceitos frente ao envelhecimento são conhecidos por ageism (idadismo), e envolvem as atitudes de discriminação frente às supostas perdas ou diminuição da capacidade cognitiva, até à produção e à vida afectiva (Palmore, 1999). O ageismo 
acaba por induzir a diminuição na participação das pessoas mais velhas, como uma forma de exclusão. Por certo, algumas dimensões físicas e características de personalidade podem modificar-se com a idade.

Como apontado por França (1989), dos aspectos que frequentemente se acentuam estão: a regularidade do ritmo, método, gosto, pontualidade, rigidez, atenção concentrada, disciplina, prudência, vocabulário, memória para fatos passados, paciência e exatidão. Dos aspectos que podem diminuir estão: a audição, visão, olfato, precisão manual, tato, flexibilidade, rapidez de ritmo, adaptação, memória para fatos recentes, energia e atenção difusa.Grande parte destas alterações não impedem que os trabalhadores mais velhos sejam capacitados para o trabalho, respeitando-se alguns limites, como os da força física, a motricidade e a percepção visual, que, por sua vez, podem ser contornadas ou corrigidas com o uso de aparelhos, lentes, exercícios ou a revisão ergonômica do ambiente de trabalho.

Alguns movimentos podem levar à fadiga, como por exemplo ficar de pé por longos períodos ou tarefas que requeiram atenção difusa. Ganham as atividades que dependam do intelectual, da experiência ou do discurso que progridem com a idade. Conforme apontado por Seminério (1991), o declínio intelectual só acontece quando o compromisso do cérebro for bastante acentuado e/ou o desuso for prolongado e contínuo. É preciso atentar que o processo de envelhecimento depende de diversos aspectos biopsicossociais que variam de pessoa a pessoa. E, o modo mais eficaz para combater os preconceitos contra os trabalhadores mais velhos é através da educação ao longo da vida (Palmore,1999).

Uma alternativa para reduzir os preconceitos frente ao envelhecimento é propor uma ampla discussão, desencadeada pelos meios de comunicação, escolas e organizações. Estudos e pesquisas preliminares são necessários para que as políticas sejam articuladas, e as parcerias sejam estabelecidas com diversos sectores da sociedade, dentro de uma perspectiva intergeracional, multidisciplinar e interinstitucional.

No Brasil, uma das prioridades da Política Nacional do Idoso² é a integração das gerações, dos serviços comunitários e de voluntariado, facilitando o bem estar das crianças e dos idosos. A Política Nacional do Idoso faz algumas recomendações com relação à atualização dos trabalhadores - para permitir que continuem activos e competitivos no mercado - e à implantação de Programas de Preparação para a Aposentadoria (ou PPA, como conhecido no Brasil) - para aqueles que desejam

\footnotetext{
2 Em dezembro de 1994, o Ministério da Previdência e Assistência Social dispõe sobre a Política Nacional do Idoso, através da Lei no. 8.842. Em agosto de 1996, é publicado pelo MPAS o Plano de Ação Governamental Integrado para o Desenvolvimento da Política Nacional do Idoso, com a participação dos outros ministérios, além de profissionais de instituições governamentais e não-governamentais que atuam com idosos.
} 
sair da empresa. O Programa de Preparação para a Reforma (PPR) tem por objetivo apoiar os trabalhadores neste período de transição.

A reforma é mais uma etapa do desenvolvimento do homem no seu contexto. Pela interdependência dos conteúdos do passado, presente e futuro, o tema interessa a qualquer idade, devendo ser discutido tanto com o jovem que ingressa no mercado de trabalho, quanto com quem está próximo da reforma, e ainda com aqueles que já se reformaram. Sobretudo, é importante ainda conhecer quais são as atitudes dos trabalhadores frente à reforma, visando encontrar alternativas para o seu bem-estar e que dependem de uma série de outros aspectos além das pensões.

\section{Atitudes frente à reforma - perdas e ganhos}

O estudo das atitudes têm sido objecto de grande consideração pelos psicólogos sociais, mas ainda são raras as pesquisas no que diz respeito às atitudes face à reforma. As atitudes dos trabalhadores frente à reforma determinam em grande parte como eles viverão esta transição, e são importantes dados a serem tratados pelas políticas e diretrizes dos governos e organizações, contribuindo para que suas sociedades encontrem saídas que resultem em maior bem-estar para os reformados.

França $(2004,2008)$ conduziu um estudo com 517 directores de grandes organizações no Brasil e na Nova Zelândia sobre as atitudes face à reforma. As atitudes foram agrupadas em cinco dimensões positivas e quatro negativas, a partir da importância atribuída aos ganhos (vantagens) e às perdas (desvantagens) esperados na transição, tais como:

\subsection{Ganhos na reforma}

a-Mais tempo para os relacionamentos (cônjuge, filhos, pais, parentes, e amigos). b-Mais tempo para atividades culturais e de lazer (oportunidade de viajar a lazer; tempo para os "hobbies", atividades culturais/desportivas; e participação em clubes/associações).

c-Liberdade do trabalho (não ter mais que representar a empresa; não ter que gerir uma equipe; não ter mais a responsabilidade do trabalho; não ter que trabalhar sob pressão; estar livre de compromissos de horário; e ter mais liberdade para criar).

d- Novo começo (tempo para realizar trabalho voluntário; realizar um trabalho diferente; dedicar-se à educação; e participar na política). 
e-Investimentos (tempo para dedicar-se aos investimentos económicos).

\subsection{Perdas na reforma}

a-Aspectos emocionais do trabalho (compreende a perda dos desafios; da liderança; do sentimento de pertença; do poder de decisão; da responsabilidade do trabalho; do senso de ter um trabalho competitivo; e da criatividade empregada no trabalho).

b-Aspectos tangiveis do trabalho (compreende perdas mensuráveis como não mais participar nos eventos/festas do trabalho; não ter mais a secretária; perda do status; do ambiente de trabalho, do escritório e mobília; perda da oportunidade de fazer viajens de trabalho; das reuniões e contatos com clientes; do senso de estar ocupado; e a perda da rotina do trabalho).

c-Relacionamentos no trabalho (com a equipe e com os colegas).

d-Benefícios e compensações do trabalho. Esta dimensão abrange duas perdas: do plano de saúde; e dos salários e benefícios.

Diversos preditores podem influenciar as atitudes frente à reforma, e serão analisados a seguir.

\section{A importância do trabalho - uma questão de identidade}

A transição para a reforma pode provocar uma insegurança fruto da perda de status, do ambiente, do convívio com os colegas de trabalho, ou mesmo do prazer das actividades inerentes à função que acabam levando os trabalhadores a retirar-se não só das actividades produtivas, mas também do fluxo colectivo da existência (França, 1999).

Se construimos nossa identidade principalmente em função do que fazemos, a crise de identidade provocada pela perda do trabalho é semelhante às mudanças que ocorrem na adolescência, mas que desencadeiam o desenvolvimento e o crescimento psicológico (Erikson, 1997). Em outras palavras, apesar da reforma trazer à tona uma série de mudanças, pode ser vista como uma oportunidade para reflexão existencial. Erikson sugere algumas questões para esta reflexão: Como nós gostaríamos de ser chamados ou conhecidos quando ficarmos velhos? O quão independentes podemos ser? Quem seremos quando chegarmos aos 85 anos de idade ou acima, comparados ao que éramos (ou somos) na meia idade? Estas questões podem servir de base para a planificação individual da reforma. 
A identidade com o trabalho pode estar relacionada também ao envolvimento e a satisfação com o trabalho. A satisfação com o trabalho abrange a dedicação de tempo, os sentimentos positivos e à afectividade para com o emprego (Agho, Mueller e Price, 1993). Santrock (2002) enfatiza que muitos pré-reformados esperam trabalhar durante os anos da reforma. Estes resultados não foram encontrados na investigação de França (2004) em que as primeiras escolhas na reforma foram: melhorar o estilo da vida (55\%), dispender mais tempo para os relacionamentos (51\%), e trabalhar como voluntário (42\%).

Alguns autores argumentam que as atitudes dos trabalhadores em relação à reforma podem depender do envolvimento e da satisfação atribuídas ao trabalho, bem como das suas outras funções na sociedade. Cude e Jablin (1992) demostraram que o compromisso com o cargo provoca um difícil desengajamento dos trabalhadores no período da reforma. França (2004) não encontrou qualquer relação quanto ao envolvimento e a satisfação com o trabalho e as atitudes de executivos frente à reforma.

Nem todos os trabalhadores têm oportunidade de escolher a profissão. As famílias podem influenciar o caminho das profissões da mesma forma que as condições econômicas acabam empurrando os jovens para profissões nem tão desejáveis. Apesar da reforma representar uma oportunidade para mudar de estilo de vida, há pessoas que desejam continuar com a mesma actividade que desenvolvem, ou mesmo precisam continuar a trabalhar, não identificando outra possibilidade além do que sempre fizeram. Um outro factor relevante é que o interesse em continuar a trabalhar após a reforma pode ser mais sentido entre aqueles que ainda estão a trabalhar do que entre os que já estão reformados, como sugerido por Huuhtanen e Piispa (1992).

O desejo de continuar ou não a trabalhar parece depender do tipo de trabalho realizado. Dorfman (1992) observou que a importância atribuída à pesquisa ou ao trabalho criativo eram os preditores mais consistentes da satisfação para os professores que já estavam reformados. Já o estudo de Solinge (2007) não confirmou a hipótese de que a reforma difere de acordo com as condições ou características do trabalho, acesso aos recursos financeiros, ou contactos sociais do trabalhadores mais velhos.

Seja qual for a decisão das pessoas em relação à permanência ou não no mercado de trabalho após a transição para a reforma, a retenção de trabalhadores mais velhos na organização deve ser estimulada porque representa uma oportunidade de desenvolvimento permanente; horários flexíveis; e a possibilidade de experimentar e praticar novas habilidades, aptidões e interesses. É indubitável que a empresa ganhará em produtividade e lealdade tendo um empregado satisfeito, 
não importando a sua idade. Uma opção seria a alternância entre a produção e o repasse da experiência dos trabalhadores mais velhos aos mais jovens, estimulando a formação de equipes intergeracionais.

\section{O papel das organizações frente ao aumento da esperança de vida}

O desafio principal do terremoto do envelhecimento para as organizações reside em como eles irão manter no mercado os trabalhadores mais velhos, e ao mesmo tempo facilitar a adaptação e o bem-estar daqueles que desejam se reformar. A chave para este desafio está na Educação ao longo da vida - processo adoptado por diversos países e que prevê programas de educação de adultos, que podem ser voltados tanto para a continuidade no mercado de trabalho quanto para o desenvolvimento pessoal.

Os programas de educação ao longo da vida devem prever a actualização dos trabalhadores mais velhos, desde a inserção digital, novas tecnologias e metodologias; a discussão dos preconceitos contra o envelhecimento; e a integração dos trabalhadores mais velhos com os mais jovens. Para tal, as organizações devem manter seus trabalhadores mais velhos permanentemente actualizados e, ao mesmo tempo, promover a preparação para a reforma para os que desejam ou precisam sair do mercado de trabalho, respeitando sempre o livre-arbítrio do trabalhador.

A organização não é responsável pela vida das pessoas, mas pode facilitar o espaço de reflexão prévio à reforma, investindo em pesquisas, diagnósticos, parcerias, de forma a conhecer as atitudes da população em relação à reforma. O conhecimento da percepção dos trabalhadores e das políticas de Recursos Humanos é um referencial importante para que seja proposto um Programa de Preparação para a Reforma - PPR, a atualização dos trabalhadores mais velhos que desejam continuar no mercado de trabalho, e a optimização das equipes intergeracionais que irão permanecer trabalhando juntas.

\section{Aspectos metodológicos de um Programa de Preparação para a Reforma - PPR}

Uma organização ao propor um Programa de Preparação para a Reforma (PPR) está a contribuir para o bem estar actual e futuro dos seus colaboradores, independentemente da sua continuidade ou não no mercado de trabalho. O PPR deve 
contar com a participação da família, pelo menos dos cônjuges nas palestras iniciais ou nos seminários informativos.

Os departamentos de Recursos Humanos precisam estar atentos ainda para o ganho social da continuidade ou da reinserção no mercado de trabalho. Governos

54 e empresas precisam considerar a urgência de um trabalho de sensibilização frente ao ageismo e ao novo conceito de reforma, onde a importância atribuída pelas pessoas aos ganhos e perdas que se antecipam ao evento, representam as atitudes dos trabalhadores frente à reforma.

Os gestores de Recursos Humanos, pautados no conhecimento destas atitudes poderão ajudar os futuros reformados quanto ao que deve ser reforçado (ganhos) e ao que deve ser contornado/substituído (perdas), num programa de planificação para maior bem-estar. Neste novo conceito, o reformado deve ser estimulado a inserir uma atividade ou trabalho, no seu projecto de vida, mas em horário reduzido.

As estratégias do PPR devem incluir a preparação de equipes interdisciplinares, a inserção de facilitadores, a sensibilização, a realização de diagnósticos (mediante entrevistas, questionários e grupos focais), a implantação do programa, ao acompanhamento e avaliações periódicas. Num programa de preparação para a reforma (PPR) o diagnóstico da clientela tem como objectivo a descoberta, a manutenção e/ou o resgate de interesses que possam trazer um enriquecimento e estímulo à vida. Esses interesses podem ser resgatados da infância ou da juventude, adaptados e/ou transformados em um projecto maior. Assim, o participante será estimulado a desenvolver ou experimentar actividades que abranjam categorias como investimentos financeiros; desportos e lazer; saúde; política e comunidade; relacionamentos; ou $2^{\text {a }}$. carreira.

As avaliações periódicas devem ser realizadas especialmente após dois anos da reforma, período que os pesquisadores apontam como a lua-de-mel - para o constante aperfeiçoamento de temas, conteúdo das discussões e do processo do PPR. A primeira avaliação deve ser realizada nos seis meses após o início do programa, cujo objectivo é o de avaliar com o futuro reformado o seu projecto de vida, sendo enfatizados os principais resultados, acertos e as reformulações necessárias.

\subsection{Conteúdo dos programas}

Os programas devem conter dois módulos: um com conteúdos informativos e outro com conteúdos formativos que poderão ser definidos por meio da pesquisa ou do diagnóstico de atitudes e interesses da clientela pré-reformada. O módulo informativo pode ser desenvolvido por meio de websites, newsletter da organiza- 
ção, realização de palestras, seminários ou workshops visando a promoção da saúde; a revisão dos hábitos alimentares; a abordagem dos aspectos psicossocias da reforma; os relacionamentos afetivos, familiares e sociais; as actividades artístico-culturais; o voluntariado; o desporto, actividades físicas e de lazer; dicas sobre investimentos. Neste módulo seria recomendável a participação da família, ou pelo menos da parceira/parceiro.

O módulo formativo tem por objectivo o desenvolvimento de grupos de reflexão, com a adopção de facilitadores, cuja prioridade é o projecto pessoal do futuro reformado. Neste caso, é interessante contar com a participação de convidados reformados bem sucedidos e/ou empresas organizadas por cooperativas de ex-funcionários. O trabalhador deve ser estimulado a equilibrar o tempo de vida e o trabalho assim que ingressa na organização, bem como a planejar financeiramente para o futuro, constuindo um projecto de vida.

A iniciativa, a persistência, e a responsabilidade do trabalhador diante do próprio futuro são aspectos primordiais para o sucesso na reforma, e devem ser incentivados no projecto de vida. Este projeto deverá ser construído paulatinamente durante o programa, com o apoio de um facilitador, prevendo-se ajustes a serem inseridos durante e após o momento da reforma.

Os conteúdos do programa podem ser subdivididos em factores de sobrevivência ou de risco e factores de bem-estar. Os factores de sobrevivência ou de risco contêm a preparação financeira, a promoção da saúde, e a melhoria da qualidade de vida colectiva. Os factores de bem-estar abrangem a diversidade e alocação de tempo para as actividades, a intensificação dos relacionamentos sociais e familiares, e ainda o trabalho e o empreendedorismo.

\subsubsection{Fatores de sobrevivência ou de risco}

\subsubsection{A preparação financeira}

A perda do poder aquisitivo na reforma é considerada a maior perda, um fantasma que assusta a muitos, especialmente considerando que poucos são os privilegiados que possuem planos de previdência do estado e/ou privados. Mesmo nas organizações onde os trabalhadores desfrutam de maior equilíbrio financeiro, e contribuem para um fundo de pensão privado da empresa, o projecto de futuro não passa apenas pelo que recebem no final do mês, mas em como capacitar as pessoas para gerir estes recursos.

Um outro aspecto que não está sendo discutido pelos bancos e fundos de pensão são as atitudes que levam as pessoas a economizar ou não para a reforma (Hershey, 
Henkens \& Van Dalen, 2007). Informações sobre investimentos são importantes, mas não são suficientes para capacitar as pessoas a lidar com o dinheiro. Isto vale para as outras questões sobre a reforma, que devem ser discutidas entre os interessados por meio de workshops sistemáticos.

56 A equipe que implantará o PPR na organização deverá convidar profissionais da área financeira para discutir o tema com os pré-reformados. É importante que esse profissional conheça previamente o perfil econômico da clientela com a qual irá trabalhar, de forma que a sua abordagem seja coerente com a realidade do grupo.

Um outro determinante na decisão e adaptação à reforma para os homens e mulheres é a possibilidade do evento coincidir com a dependência financeira dos filhos/netos ou com a assistência a um familiar idoso, principalmente porque a renda deverá diminuir e as despesas poderão aumentar. Portanto, a preparação deve incluir diversas situações, sendo simulados salários, outras receitas, bens, dividas e investimentos e a reflexão sobre o total estimado necessário para viver na reforma, e manter os mesmos padrões de vida a médio e longo prazo.

Ao final do workshop os participantes devem ter condições de calcular o valor mínimo mensal que precisam economizar para viver com conforto 20 a 40 anos de reforma, e em como re-investir esses recursos durante a reforma.

\subsubsection{A promoção de saúde}

O tipo de trabalho pode ser considerado um factor de risco, especialmente se este gerar grande nível de estresse. Na outra ponta, a inactividade e a falta de perspectivas na reforma também pode gerar sentimentos de ansiedade e depressão que provocam doenças psicossomáticas (França, 1999). A reforma em si necessariamente não prejudica ou beneficia o estado de saúde, mas a falta de controlo sobre o acontecimento pode trazer efeitos negativos para a saúde, e mais ainda se a reforma for percebida como não desejada (Solinge, 2007).

A promoção de saúde deverá abranger não apenas as visitas periódicas ou palestras do clínico geral, mas os workshops e grupos de discussão nas organizações, de forma que o pré-reformado possa adoptar um estilo de vida mais saudável. Neste novo estilo se incluem as atividades de lazer, os relacionamentos harmoniosos, o controlo do tabagismo, a redução do consumo de bebidas alcoólicas, boa higiene de sono, redução do estresse, a boa alimentação e o exercício físico.

A possibilidade de não contar com o plano de saúde patrocinado pela empresa representa a segunda maior perda na reforma, depois da questão financeira. Portanto, não só a promoção de saúde deve fazer parte do PPR, mas a discussão 
sobre a continuidade do plano de saúde para o reformado, e formas de assistência a saúde que possam garantir a tranquilidade no futuro.

\subsubsection{A influência da qualidade de vida colectiva no bem estar individual}

A preparação para a reforma é um processo individual mas que depende do colectivo. A forma como as pessoas percebem e avaliam os indicadores ambientais, socio-econômicos e politicos, influenciam positiva ou negativamente a planificação para o futuro.Esta percepção dos pré-reformados quanto à qualidade de vida do país e dos seus indicadores, é tão relevante quanto a avaliação objectiva divulgada por organismos internacionais como a ONU, OMS ou Banco Mundial.

$\mathrm{Na}$ pesquisa realizada por França (2004) com os executivos brasileiros e neozelandeses, foi visível a diferença da influência da qualidade de vida colectiva na planificação da reforma. No caso específico dos executivos brasileiros, a avaliação dos indicadores sugere aspectos a serem inseridos num programa de preparação para a reforma, como por exemplo a busca de formas alternativas para ajudar colectivamente a sociedade, reduzir a violência urbana e a inequidade social.

Estas acções chamadas de responsabilidade social estão sendo realizadas por meio de uma ponte dinâmica de discussão entre os doadores (funcionários da organização) e os receptores (comunidade). Após a reforma, a continuidade da participação dos reformados pode ser efetivada por meio da sua ligação com a associação dos reformados. Esta é uma das formas de se manter um vínculo produtivo entre a organização, seus trabalhadores, os reformados, e a comunidade. Inúmeros são os benefícios deste tipo de acções tanto para a sociedade que recebe, para a auto-estima dos trabalhadores/reformados que participam, como para a imagem da organização.

\subsubsection{Factores de bem-estar}

\subsubsection{Diversidade e equilibrio na alocação de tempo para as actividades}

Um aspecto de extrema importância é saber utilizar o tempo livre em função das prioridades pessoais. A reforma é um tempo em que é possivel aproveitar a vida e as oportunidades que as pessoas têm diante de si. O trabalho, voluntário ou remunerado, pode estar incluído numa nova distribuição do tempo, mas de preferência com uma carga horária reduzida.

França (2004) aponta que a maioria dos executivos da sua pesquisa trabalhava em média mais de 50 horas por semana. O pouco tempo que normalmente sobra, 
justifica a quase que ausência de lazer, de dedicação à família, aos amigos, à promoção da saúde e educação. O desequilíbrio na alocação do tempo entre o trabalho e a vida pessoal é prejudicial à saúde e contraprodutivo para as organizações, pois impede a reciclagem, a oxigenação de idéias e o desenvolvimento da criatividade. Sobretudo a rotina exagerada de trabalho e as horas extras desnecessárias provocam dificuldades para os trabalhadores administrarem o tempo livre na reforma.

De modo a facilitar o equilíbrio entre o trabalho e a vida pessoal, as organizações devem apresentar estratégias e flexibilidade de horários para seus trabalhadores. Esta flexibilidade, vital para a saúde e bem estar, talvez seja a maior dificuldade que o aposentado brasileiro enfrenta. Tendo passado a maior parte da vida dentro de um escritório, o reformado nem sempre sabe o que fazer com o tempo livre. É preciso estar atento e desenvolver seus interesses, reaprendendo a utilizar o tempo livre a seu favor.

As actividades na reforma representam verdadeiros antídotos contra a depressão, pois favorecem a incorporação de novas opções de identidade social e de reforço na auto-imagem e auto-estima. As actividades devem partir dos interessses dos participantes identificadas no diagnóstico inicial, mas sempre que possível a equipe deverá apresentar novas alternativas, que tenham preferencialmente o cunho de dar e receber na comunidade ou o usufruir da relação com a natureza, seja uma caminhada na praia ou na montanha.

Fundamental ainda é a formação de cooperativas, as redes comunitárias e a parceria com instituições sociais, universidades e grupos sociais e de lazer de forma a que os reformados possam continuar a sua participação social independentemente do seu trabalho formal ou da organização para a qual trabalhou. O reformado é aquele que pode multiplicar sua experiência para outros que estão iniciando a vida profissional ou mesmo para os que se encontram na fase de preparação para a reforma, num círculo valioso de experiências e intercâmbios.

\subsubsection{A intensificação dos relacionamentos sociais e familiares}

Muitos acreditam que na reforma os contactos sociais podem diminuir, principalmente para as pessoas que cultivaram amizades apenas no ambiente do trabalho. De forma geral, as pessoas a proximam-se pelos interesses que têm em comum, e o trabalho propicia um ambiente de encontro de pessoas e afinidades. Todavia, se os interesses e as actividades forem diversificados, mais ampliado será também o seu círculo de amizades.

O PPR deve considerar o resgate das antigas amizades e a busca de novas participações nos mais diferentes grupos sociais. A busca do pré-reformado pelo 
engajamento e pela continuidade de actividades sociais coerentes com seus interesses será brindada por uma variedade de situações que trarão enriquecimento e sentido para a vida.

Embora não seja uma regra geral, o habitual é que a reforma coincida com a época dos filhos entrarem para a faculdade, estarem casados, ou já terem seus próprios filhos. No caso dos filhos terem uma relação de dependência dos pais, a reforma pode dar uma sensação de insegurança pela perda econômica num momento de muita despesa.

Se o filho está saindo de casa, é uma oportunidade do casal ter mais tempo para sua intimidade, embora esta saída dos filhos pode provocar um sentimento de "síndrome do ninho vazio", no momento em que a mãe (ou pais) vê (em) esvaziada(os) o seu papel de cuidador(a) do (a) filho (a).

O casal deve ser estimulado a refletir sobre as actividades de interesses comuns, embora deva ser reconhecida a importância dos projectos individuais. A família é a rede de suporte mais importante na reforma. Portanto, se houver possibilidade, seria desejável identificar ou levar o futuro aposentado a refletir sobre os interesses dos membros do seu círculo familiar desde o cônjuge, os filhos, netos e demais familiares que residam e/ou representem importantes referências/ influências na sua vida.

A vida do casal pode ser representada por dois círculos que formam uma interseção que representa a díade do casal mas, cada círculo, tem uma parte que é individual a cada cônjuge. É fundamental que o futuro reformado tenha consciência de que alguns de seus projectos podem e devem ser compartilhados com o parceiro. Por outro lado, nada impede que ele vá de férias para um lugar onde possa pescar ou jogar tênis, se esta é a sua prioridade de lazer, sem que seja acompanhado pelo cônjuge. O problema se dá quando ele planeja realizar esse lazer em conjunto com a parceira que não aprecia tanto quanto êle a pescaria ou o tênis.

A divisão de tarefas domésticas e as obrigações familiares são outros aspectos que devem ser abordados, especialmente considerando que o homem na nossa cultura não é, em geral, muito afeito a vida doméstica. É preciso que ele participe desta função que é do casal, e por vezes gera conflitos quando o peso fica apenas para o lado feminino.

O apoio familiar é um dos preditores mais preponderantes para a qualidade de vida na reforma (Smith \& Moen, 1998; Vinick e Ekerdt, 1991; França, 2004, 2008). Isto porque os reformados terão mais tempo disponível para si e a convivência nesta fase inicial pode ser acompanhada por algumas crises no casamento. Entretanto, 
se o casal tem um nível satisfatório de intimidade e entendimento, com mágoas já resolvidas, é mais fácil que as adversidades sejam superadas.

Assim, a reforma pode se constituir num teste para o casamento e pode significar uma mudança de rotina para todos que vivem com o reformado. Um casamento 6o infeliz ou mesmo uma dificuldade de relacionamento com os filhos pode resultar na falta do prazer em passar mais tempo em casa. A reforma nesse caso é sentida como um transtorno ou o fim de um refúgio. No que se refere ao homem que irá se aposentar e cuja esposa não trabalhe, o retorno ao ambiente doméstico pode requerer algumas adaptações a serem discutidas entre o casal. Algumas esposas podem estar satisfeitas com a rotina de vida que por muitos anos não incluiu a companhia integral do marido. A manutenção do casamento na reforma poderá depender também do desenvolvimento de outras actividades, na aceitação do espaço do outro, e na divisão das rotinas familiares e domésticas de casa.

Se a esposa trabalha, o facto de o marido estar em vias de se aposentar pode significar para ela uma chance de juntar-se a ele na decisão da reforma e viverem momentos de maior liberdade, que antes, por conta do trabalho, não era possível. Entretanto, esta não coincidência do momento da reforma poderá representar um impasse para os cônjuges na decisão.

A companhia parece ser essencial no casamento das pessoas mais velhas, embora não signifique que um fará aquilo que o outro goste. Algumas pessoas reclamam da individualidade exacerbada dos parceiros e isso normalmente acontece porque um dos dois espera que o outro preencha o espaço deixado pelo trabalho. Vinick e Ekerdt (1991) apontaram que muitas donas de casa americanas sentiram a falta de privacidade após a reforma dos maridos. Elas se sentiam monitoradas em suas rotinas, e a adaptação do casal no primeiro ano de reforma torna-se difícil. Homens e mulheres com saúde e situação financeira adequada, bem como uma história de compatibilidade marital, têm motivos para acreditar que a felicidade na reforma seja alcançada, mas é preciso ter consciência das mudanças que se sucederão.

Geralmente, após muitos anos de convivência as pessoas já aprenderam a aceitar suas diferenças e a valorizar o que têm em comum. Olhar para trás, fazer planos juntos e falar sobre o que fizeram faz parte da convivência de um casal que tenha uma relação de muitos anos. Se o casal divide uma história de cumplicidade, irá aprender a tirar proveito do tempo livre e apreciar mais a companhia do outro, a menos que hajam muitos arrependimentos ou mágoas não resolvidas ao longo do casamento. Esta cumplicidade poderá ajudar a contornar as dificuldades, mesmo nas relações sexuais, que podem até diminuir na freqüência ou intensidade, se comparadas ao vigor sexual da juventude, sem que necessariamente afectem o desejo e a qualidade do relacionamento do casal. 
Existem ainda casos de pré-reformados que são viúvos ou que vivem sozinhos. Muitos substituem a ausência do cônjuge pelas amizades e contactos com parentes. Outros andam em busca de relacionamentos afectivos duradouros. Alguns trabalham sem parar passando a maior parte do tempo fora de casa. Há indivíduos que declaram viver bem sozinhos e outros que nunca aceitaram o facto de não ter alguém com quem dividir a casa e a vida. Alguns se realizam com namoros sem compromissos, mas para outros a falta de um parceiro pode levar à incapacidade de realizar os planos na vida pós-laboral.

Tantos factores influenciam a planificação, decisão e adaptação à reforma, que os membros da família devem ser ouvidos e convidados a participar nas palestras de sensibilização do PPR e de outras sessões que abordem o processo de reforma e a importância do apoio do grupo familiar nesta transição de vida.

As mudanças demográficas alongaram também a vida entre as gerações e o valor e importância dos avós no contexto familiar. De acordo com Bengtson (2001) a força e a resistência da solidariedade intergeracional atravessam o tempo, tornando as relações multigeracionais (que envolvem três ou mais gerações) cada vez mais importantes e diversas, se expandindo em termos de estrutura e funções.

Sem dúvida que ser avó ou avô é uma oportunidade de renovação, especialmente se o papel dos avós for mais voltado para o lazer e prazer intergeracional, e não obrigação. Quanto a isto, a investigação de Reitzes e Mutran (2004) indicou que o trabalho é importante para os homens e mulheres, mas o papel de ser avô/avó preenche igualmente a vida dos homens e das mulheres mais velhos.

Em alguns casos, os vínculos multigeracionais são mais importantes que os laços das famílias nucleares, por exemplo os parceiros dos pais/mães, dos avôs/avós, provendo o bem-estar e apoio aos seus membros. Como apontado por Bengtson (2001), a crescente prevalência e importância dos laços multigeracionais representarão um novo recurso valioso para as famílias do século 21.

A organização deve propor workshops que abordem a importância do apoio familiar na reforma. Neste aspecto, as empresas podem ajudar a família e ao futuro reformado a se acostumar, gradativamente, com a idéia da disponibilidade do tempo e de como administrá-lo entre o privado, o familiar e o colectivo.

\subsubsection{Trabalho, empreendedorismo e novos negócios}

Aprendemos por muitos anos que o trabalho dignifica o homem e a ausência dele pode levar à diminuição da auto-estima. Por conta disto, é aconselhável que 
a inserção do trabalho voluntário ou da actividade laborativa faça parte da vida dos reformados, mas em horários reduzidos.

Muitos reformados desejam investir na abertura de um novo negócio. Para que os riscos de fracasso sejam evitados, sugere-se a organização em cooperativas.

62 Dentro do PPR, as organizações portuguesas de a poio a novos negócios e a futuros empreendedores devem ser convidadas para workshops com futuros reformados com a intenção de gerenciar um negócio.

Uma rede de contatos e de conexões estabelecida dentro e fora dos grupos facilita a formação de cooperativas e associações com os mesmos objectivos. No diagnóstico do PPR, a organização poderá identificar os futuros reformados com interesses comuns, e disponibilizar espaço para que as pessoas se encontrem e discutam suas idéias. Estes encontros preferencialmente sistemáticos, devem acontecer de acordo com o interesse dos grupos e disponibilidade da organização.

\section{Projetos intergeracionais}

A escassez de recursos para a aprendizagem de adolescentes e idosos pode conduzir os governos a utilizarem projetos ou programas intergeracionais de forma a beneficiar estes dois segmentos populacionais, onde os últimos podem servir como mentores dos primeiros (Newacheck e Benjamin, 2004). Os projetos intergeracionais são extremamente motivadores pela troca que proporcionam.

O convívio satisfatório das equipes intergeracionais gera inúmeras oportunidades de intercâmbio utilizando por um lado a experiência, o patrimônio, a memória do trabalho, e por outro, a frescura de novos métodos e tecnologias. De facto, o património é algo que demora a ser construído, e por maior que seja o valor da tecnologia, que os mais jovens dominam com facilidade, a história foi criada por aqueles que a vivenciaram e deveria ser repassada aos jovens pelos mais velhos.

Além disso, os trabalhadores mais velhos ajudam a criar um sistema de "pertença" que é muito importante para a integração das equipes. Reter bons trabalhadores implica oferecer treino e actualizações constantes, numa perspectiva de desenvolvimento integral. Trabalhadores jovens e mais velhos são elementos riquíssimos e complementares a qualquer organização, sem contar com o benefício da integração e solidariedade entre as equipes, que podem gerar motivação e produtividade. 


\section{Conclusão}

Dentre as consequências da reforma estão o alto custo das previdências e a manutenção da saúde. Uma das estratégias mais eficazes para lidar com este desafio é proporcionar aos trabalhadores a possibilidade de planificação do futuro, preparando os que querem reformar-se, ao mesmo tempo que actualizando e mantendo aqueles que desejam continuar no mercado do trabalho.

A equação educação-trabalho-reforma não precisa seguir necessariamente esta ordem, mas a empresa, o governo, e o próprio trabalhador devem investir colectivamente na abertura de oportunidades frente à necessidade de actualização, auto-desenvolvimento, e aprendizagem permanente dos trabalhadores mais velhos. É, por certo, desejável uma parceria entre as instituições, e quatro pontos merecem ser destacados com relação à preparação para a reforma:

O primeiro diz respeito à importância do trabalho na vida das pessoas e da sociedade. Muitas organizações hoje reconhecem que não devem abrir mão de um recurso humano, especialmente quando houve um alto investimento em sua especialização. A organização que descarta facilmente uma mão-de-obra saudável que quer continuar contribuindo, está jogando fora não apenas sua experiência, mas a história da organização. Assim, a prioridade deve ser a retenção, a actualização do trabalhador e a adocção de um contrato de trabalho com horários reduzidos.

O reformado que deseja continuar a trabalhar, deve também desenvolver-se mental e fisicamente, bem como manter os seus contactos sociais e auto-estima, tão importantes ao bem-estar e à promoção da saúde. Então, desde que haja possibilidade no mercado de trabalho, deve ser priorizado o emprego com carga horária reduzida para atender não só aos reformados mas também aos estudantes, e mães com filhos menores. É necessário uma ampla discussão entre o governo e diversos sectores da sociedade para um consenso sobre a criação de um ajuste/estímulo na redução de impostos/encargos, que não sejam restritivos e que favoreçam a contratação daqueles que desejam trabalhar a meio tempo.

O segundo ponto fundamental é a garantia de uma poupança mínima para o futuro. Neste caso, é relevante descobrir as atitudes que levam as pessoas a economizar, bem como a viabilidade de um processo educativo que estimule a planificação. Sabemos que o montante que o trabalhador acumula não depende necessariamente do quanto ele ganha, mas do quanto ele gasta, ou do que aprendeu a economizar com a sua família, amigos, escola ou mesmo por influência da sua organização ou da mídia.

O terceiro ponto é a adoção do PPR paralelo ao plano de pensão do estado e de previdência complementar, que numa visão multidimensional, atrele a educação e a planificação financeira ao projecto de vida pós-reforma. A poupança para o 
futuro deve ser iniciada assim que o empregado ingressa na empresa, seja por meio da previdência do estado ou de um plano de previdência privada.

Dentre os mais diversos temas que podem estar presentes no PPR estão: a discussão sobre situações familiares; a divisão das tarefas domésticas; as amizades

64 e a melhoria do relacionamento afetivo e familiar; a busca de projectos que envolvam o parceiro e interesses pessoais; a realização de passatempos, actividades culturais, físicas e de lazer; informação sobre investimentos financeiros; o retorno aos estudos; o voluntariado e/ou a descoberta de uma segunda carreira. Estes interesses/conteúdos devem ser identificados previamente no diagnóstico e associam-se ao projecto de vida, fundamental no PPR. O projecto de vida deve ser reavaliado pelo futuro reformado de tempos em tempos, por meio de reflexões e discussões sistemáticas, com o apoio de um facilitador.

O último e quarto ponto refere-se à acção colectiva da sociedade contra os preconceitos em relação ao envelhecimento. Os programas intergeracionais nas organizações beneficiam tanto os jovens que precisam de tutores experientes, quanto a estes últimos que necessitam de se atualizar e serem reciclados sobretuo no que se refere a novas metodologias e inserção digital. A organização, ao implantar programas intergeracionais focados no intercâmbio, pautados na solidariedade e na produção colectiva de projetos prioritários, irá favorecer a harmonia e o espírito de equipe, estimulando uma produtividade mais criativa e duradoura.

\section{Bibliografia}

Agho, A. O, Mueller, C. W, \& Price, J. L. (1993). Determinants of employee job satisfaction: An empirical test of a causal model. Human Relations, 46(8), 1007-1028.

Allport, G. (1954). The Nature of Prejudice, Addison-Wesley.

Bengtson, V. L. (2001) Beyond the nuclear family: The increasing importance of multigenerational bonds. Journal of Marriage and Family. 63 (1); 1-16.

Cude, R. L., \& Jablin, F. M. (1992). Retiring from work: The paradoxical impact of organizational commitment. Journal of Managerial Issues, 4(1), 31-45.

Dorfman, L. T. (1992). Academics and the transition to retirement. Educational Gerontology, 18(4), 343-363.

Erikson, E. H. (1997). The life cycle completed: A review. [Versão extendida]. New York: W. W. Norton \& Company.

Hershey, D. A., Henkens, C. I. J. M., \& Van Dalen, H. J. (2007). Mapping the minds of retirement planners: A cross-cultural perspective. Journal of Cross-cultural Psychology,38, 361-382.

França, L. H. (1989). O resgate do tempo. Boletim técnico do Senac, 15(2), 97-111.

França, L. H. (1999). Preparação para aposentadoria: desafios a enfrentar. In R. P. Veras (ed.) Terceira idade: alternativas para uma sociedade em transição (pp. 11-34). Rio de Janeiro, BR: Editora Relume-Dumará/Unati/UERJ. 
França, L. H. (2004). Attitudes towards retirement: a cross-cultural study between New Zealand and Brazilian executives. Auckland, 456 p. Tese de Doutorado em Psicologia Social, Departamento de Psicologia, The University of Auckland, New Zealand.

França, L. H. (2008). O desafio da Aposentadoria: O exemplo dos executivos brasileiros e neozelandeses. Rio de Janeiro: Rocco.

Huuhtanen, P., \& Piispa, M. (1992). Work and retirement attitudes of 50- to 64-year-old people at work and on pension. Scandinavian Journal of Work, Environment \& Health, 18(Suppl. 2), 21-23.

Newacheck, P. W. \& Benjamin, A.E. (2004). Perspective: Intergenerational Equity And Public Spending. Health Affairs, 23(5), 142-146.

Palmore, E. (1999). Ageism: Negative and positive. New York: Springer Publishing Company.

Reitzes, D.C., \& Mutran, E. J. (2004). Grandparent Identity, intergenerational identity, and well-being. The Journals of Gerontology: Social Sciences, 59B(4), 213-219.

Santrock, J.W. (2002). Life-span development (8th ed.). New York: McGraw-Hill Higher Education.

Seminério, F. L. (1991). Conflitos existenciais na terceira idade [Third-Age's existential conflicts]. Arquivos Brasileiros de Psicologia Aplicada, 43, 1-2.

Solinge, H. (2007). Health change in retirement: A longitudinal study among older workers in the Netherlands. Research on Aging, 29(3), 225-256.

Smith, D.B., \& Moen, P. (1998). Spousal influence on retirement: His, her, and their perceptions. Journal of Marriage \& the Family, 60(3), 734-744.

United Nations (2006). Population Ageing 2006 [Graph]. New York: United Nations. Consultado em 20/06/2009, http://www.un.org/esa/population/unpop.htm

Vinick, B. H. , \& Ekerdt, D. J. (1991). Retirement: What happens to husband^^wife relationships? Journal of Geriatric Psychiatry, 24(1), 23-40.

\section{Retirement Planning Program: Personal and Collective Responsibility}

One of the consequences of the advances of medicine and the fall of fertility was the increase in life expectancy, observed in the developing and developed countries. Thus, the biggest challenge for this century will be to maintain older people active, independent and participative, as recommended by World Health Organization. The world of work has to guarantee workers' freedom of choice, between retirement and continuation in the labour market, as well as the necessary measures for their future well being. In this article ageism (prejudice against age), attitudes towards retirement, renovation of elderly workers, as well as the Retirement Planning Program will be discussed. Furthermore, intergenerational projects will also be presented for an exchange of knowledge and experience between older and younger workers, as a valuable transfer process of human and historical knowledge within organizations.

KEY-WORDS: retirement; attitudes; prejudice; Retirement Planning Program; work; intergenerational projects. 


\section{Préparation à la retraite: responsabilité individuelle et collective}

Une des conséquences du progrès de la médecine et de la chute de la natalité a été l'augmentation de l'espérance de vie observée dans les pays développés autant que dans les pays émergeants. Ainsi le plus grand défi de ce siècle sera garder actives les personnes âgées et les rendre indépendantes et participantes, comme recommande l'organisation mondiale de la santé. Dans le monde du travail il faut garantir le libre choix du travailleur face à sa retraite ou continuité dans le marché du travail ainsi que les mesures à prendre pour son bien-être dans l'avenir. Cet article traite des préjugés contre l'âge et les attitudes devant la retraite, l'actualisation de la main d'oeuvre mature et le programme de préparation à la retraite (PPR). Les projets intergénérationnels interéchangeant l'expérience et le savoir des plus jeunes et plus agés sont présentés comme un processus de transfert et valorisation du patrimoine humain et historique de l'organisation.

MOTS-CLÉS: retraite; attitudes; préjugés, programmes de préparation à la retraite; travail; projets intergénérationnels. 